\title{
Geoff Timmins, et al. Teaching and Learning History, London: Sage Publications, 2005.
}

Gregory M. W. Kennedy, York University

In the past generation, there has been a "deluge of reflexive analysis" within the historical profession (9). The ultimate question remains "what is history for" (10)? As an undergraduate, I stared at the abyss

presented to me by postmodernism, and railed against what I perceived as poor teaching methods and especially arbitrary marking. Now, as a senior PhD student contemplating my own leap into the profession, I must define my own approach with a "statement of teaching philosophy" for potential employers. Teaching and Learning History, targeted at the history teaching profession and especially new members, made me familiar with the issues, the terminology, and perhaps most importantly, some of the different approaches taken by other departments and faculty.

The authors' aim is to "contribute to the process of curriculum planning in undergraduate history programmes" and discuss methods of implementation (2). They accomplish this through a review of a range of issues based on the History Benchmarking Statement, a policy document issued by the British government's Quality Assurance Agency in 2000 listing five considerations for honours degree students, namely:

-historian's skills and qualities of mind

-content criteria

-progression between stages

-approaches to teaching and learning

-assessment.

Past Imperfect

13 (2007) | @ | ISSN 1192-1315 
After an introductory chapter that reviews the debates within the profession since the 1960s (especially the rise of "new" history, the postmodernist challenge, and higher enrolments), each of the above considerations is broken down in its own chapter.

The book's sources include prominent studies and essays on the subject from across the English-speaking world, a sample of history department websites, and surveys of several British higher education institutions. One of the book's strengths is that it does not devolve into a protracted narrative of theoretical debate, but simply encapsulates the main positions from leading theorists in order to break down each issue. In fact, the authors consistently refrain from directly stating their own theoretical views or preferred solutions. They employ an approach that summarizes the issues at hand and the strengths and drawbacks of different methods. For example, the chapter on "approaches to teaching and learning" effectively contrasts seminars, lectures, and newer workshop and internet-based models, all with a view to promoting active learning. Particularly interesting were suggestions on how traditional lecture formats and examination assessments could be adapted. The authors underline that newer models work best "where they reinforce traditional learning" (159). The surveys, though far from exhaustive, provided a tangible dimension to the discussion. Among the surprising results was that 11 of the 31 departments surveyed had not increased opportunities for senior students to pursue independent learning outside of traditional dissertations, which the authors reasonably argue should be a universal feature of history programmes (45).

An important theme of the book is transparency for both teachers and taught. This was most evident in the chapter on assessment, where the authors rightly emphasize the need for clear criteria and "statements of attainment" (184). The chapter also 
stresses the importance of transparency for the issues of progression, content criteria, and differentiation, (the process by which some students are directed into honours programs and senior seminars or awarded funding and mentorship opportunities). Indeed, the authors persuasively argue that "deep" learning for undergraduates is not just analysis of more detailed content but also includes starting students on an understanding of "the nature of history as an academic discipline" (95). Since power is a marked feature of any teacherstudent relationship, and evaluation the ultimate exercise of it, approaches such as self, peer, and group-assessment can help students understand and use assessment criteria. In a case study of five British universities, the authors found a wide spectrum from those that treated criteria as simply a broad framework, to those that used them as detailed specifications for individual assignments. Still, they note, few institutions have developed criteria that adapt to the progression and differentiation supposedly inherent in their programmes (191).

In the end, the authors do not tell us what they think history is for. In keeping with the general tone of the book, they emphasize that "all historians have to construct their own answers to these questions" (34). Nevertheless, they effectively argue that the conventional "content versus skills" paradigm is a "chimera" and that a wider perception of skills is needed. The profession has long had a "craft" orientation and the craft's skills, the authors attest, may provide the common core that theory and content seem incapable of creating $(104,131)$. While there are few true history "vocations" (beyond a burgeoning public history sector), the high level tasks inherent in a history degree could be applicable to many workplaces, and some departments have even set up work placements for senior students. Overall, however, the profession has tended to emphasize 
its own procreation and proliferation (i.e. graduate studies) as its ultimate end, to the exclusion of exploring new opportunities to challenge and provide for its students.

A subject neglected by the book, especially given the authors' emphasis on the challenge of the sheer number of undergraduates, is how to incorporate non-history majors. Since these students are increasingly prevalent in introductory and survey courses, this raises new questions about the purpose of the courses offered and the programme generally. What are these students' needs and are they ignored in favour of the "true" history student? How can a holistic approach be implemented for students who take just a few history courses as options? Should faculty seek to convert or simply enrich these students' interests?

Another implication of this book worthy of further development is the tension between historians as individuals and members of a profession. While laundry lists of options and examples are provided, the oft-noted collegial resistance to any degree of "compulsion" challenges even general considerations of assessment criteria or progression and differentiation. What degree of collective enterprise and regulation would balance our responsibilities to students and our own freedoms? To what degree should the state, increasingly the "paymaster" of higher education, expect to be able to proscribe or even dictate standards - tying money to results? Should departments be more transparent as to their particular approaches and methods, helping undergraduates make better choices on where to attend university in the first place?

Perhaps the best indication of the success of this book is the breadth of questions it raises, and the answers it suggests without proscribing an ideal solution. Eminently practical, the authors cut through the theoretical debates and bias to present a summary of the 
basic issues and options all history departments face in the new millennium. Teaching and Learning has certainly helped me more holistically consider my own bias, providing a useful checklist of issues for me to consider as I prepare statements of teaching philosophy and course syllabi. 